\title{
Enclosure of a Keggin-type heteropolyoxometalate into a tubular $\pi$ - space via hydrogen bonds with a nonplanar Mo(V)-porphyrin complex forming a supramolecular assembly $\dagger$
}

\author{
Atsutoshi Yokoyama, ${ }^{a}$ Takahiko Kojima ${ }^{*^{b}}$ and Shunichi Fukuzumi* ${ }^{* a, c}$ \\ Received (in $X X X, X X X)$ Xth $X X X X X X X X X 200 X$, Accepted Xth $X X X X X X X X X 200 X$ \\ First published on the web $X$ th $X X X X X X X X X 200 X$ \\ DOI: 10.1039/b000000x
}

A 2:1 supramolecular assembly composed of a non-planar $\mathrm{Mo}(\mathrm{V})$-porphyrin, $\left[\mathrm{Mo}(\mathrm{DPP})(\mathrm{O})\left(\mathrm{H}_{2} \mathrm{O}\right)\right]^{+}$

(1) $\left(\mathrm{DPP}^{2+}\right.$; dodecaphenylporphyrin), and a Keggin-type heteropolyoxometalate (POM), $\alpha-[(n-$ 10 butyl $\left.)_{4} \mathrm{~N}\right]_{2}\left[\mathrm{SW}_{12} \mathrm{O}_{40}\right]$ (2), was formed via hydrogen bonds. The crystal structure was determined by

$\mathrm{X}$-ray crystallography to clarify that the POM was enclosed into a $\pi$-space of a supramolecular porphyrin nanotube by virtue of hydrogen-bond network. In contrast to the formation of the $2: 1$ assembly $\left(\left[\left\{\mathrm{Mo}(\mathrm{DPP})(\mathrm{O})\left(\mathrm{H}_{2} \mathrm{O}\right)\right\}_{2}\left(\mathrm{SW}_{12} \mathrm{O}_{40}\right)\right](3)\right)$ between 1 and $\left[\mathrm{SW}_{12} \mathrm{O}_{40}\right]^{2-}$ in the crystal, it was revealed that those two components form a 1:1 assembly in solution in light of the results of

15 MALDI-TOF-MS measurements in PhCN. Variable-temperature UV-vis spectroscopic titration allowed us to determine the thermodynamic parameters for the formation of the $1: 1$ supramolecular assembly in solution, the heat of formation $(\Delta H)$ and the entropy change $(\Delta S)$. These results provide the first thermodynamic data set to elucidate the formation process of supramolecuar structures emerged by hydrogen bonding between metalloporphyrin complexes and POMs,

20 indicating that the formation of the assembly is an entropy-controlled process rather thanan enthalpy-controlled one. Comparisons of the thermodynamic parameters with those of a planar $\mathrm{Mo}(\mathrm{V})$-porphyrin complex also highlighted high Lewis acidity of the $\mathrm{Mo}(\mathrm{V})$ centre in the distorted porphyrin.

\section{Introduction}

${ }_{25}$ Porphyrins and chlorophylls are well organized into nanoscaled supramolecular structures that perform the lightharvesting and energy- and electron-transfer functions as observed in photosynthesis. ${ }^{1,2}$ Inspired by such well-defined nanostructures of porphyrins and chlorohylls in nature,

${ }_{30}$ porphyrin nanostructures have attracted great interest because of their promise as catalysts and photofunctional nanomaterials. ${ }^{3-12}$ Extensive efforts have so far been devoted to develop well-defined nanostructures such as nanospheres, ${ }^{3,4}$ nanosheets, ${ }^{5}$ nanotubes, ${ }^{6-8}$ nanofibers ${ }^{9,10}$ and other 35 morphologies. ${ }^{11-13}$ Among them, porphyrin nanotubes (PNTs) have merited special attention, because the molecular building blocks can be easily altered to control their structural and functional properties. ${ }^{6-8}$ However, direct X-ray structural

\footnotetext{
aepartment of Material and Life Science, Graduate School of Engineering, Osaka University, ALCA, Japan Science and Technology Agency (JST), 2-1 Yamada-oka, Suita, Osaka 565-0871, Japan. E-mail: fukuzumi@chem.eng.osaka-u.ac.jp; Fax: +81-6-6879-7370

$b$ Department of Chemistry, Graduate School of Pure and Applied Science, University of Tsukuba, 1-1-1 Tennoudai, Tsukuba, Ibaraki 305-8571, Japan. E-mail: kojima@chem.tsukuba.ac.jp; Fax: (+81) 29$853-4323$

${ }^{c}$ Department of Bioinspired Chemistry (WCU), Ewha Womans University, Seoul 120-750, Korea

$\dagger$ Electronic Supplementary Information (ESI) available: Displacement of each atom of $\mathrm{DPP}^{2+}$ moiety, schematic description of the hydrogen bond network of 3, selected bond distance of 3, VT-UV-vis spectral titration, MALDI-TOF-MS of $\mathbf{3}$, crystal structure of $\mathbf{1} \cdot \mathrm{ClO}_{4}$, electrochemical measurements. See DOI: 10.1039/b000000x/
}

determination of the PNT nanostructures has still been limited. 40 On the other hand, heteropolyoxometalates (POMs) have attracted much attention due to their functionality in catalysis, ${ }^{14}$ and also as building blocks of supramolecular assemblies toward functional materials. ${ }^{15}$ In order to give POMs further functionality, supramolecular assemblies have 45 been recently developed with use of organic functional molecules such as calix-arenes ${ }^{16}$ and metalloporphyrins. ${ }^{7,17}$

In this context, we reported the X-ray crystal structure of a PNT composed of $\left[\mathrm{Mo}^{\mathrm{V}}(\mathrm{DPP})(\mathrm{O})\left(\mathrm{H}_{2} \mathrm{O}\right)\right]^{+}$(1) $\left(\mathrm{DPP}^{2+}\right.$; dodecaphenylporphyrin) unit and tetra-nuclear $\mathrm{Mo}(\mathrm{VI})$ clusters 50 which can be categorized as POMs. ${ }^{7}$ In that crystal structure, three kinds of tetra-nuclear $\mathrm{Mo}(\mathrm{VI})$ clusters, which are not stable outside of the tube structure, were enclosed by Mo(V)porphyrin via hydrogen bonds. The encapsulated POMs were

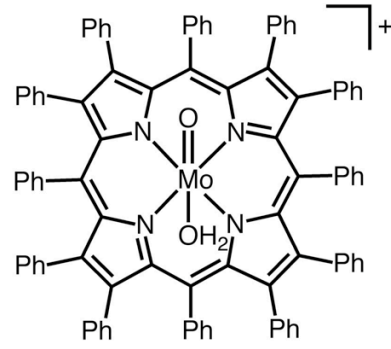

$\left[\mathrm{Mo}(\mathrm{DPP})(\mathrm{O})\left(\mathrm{H}_{2} \mathrm{O}\right)\right]^{+}$

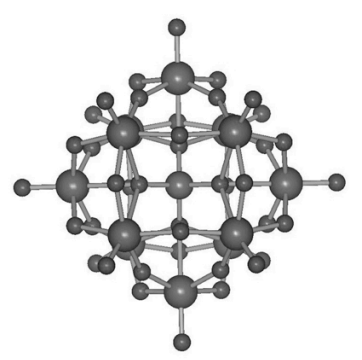

$\left[\mathrm{SW}_{12} \mathrm{O}_{40}\right]^{2-}$
Fig. 1 A non-planar $\mathrm{Mo}(\mathrm{V})$-porphyrin, $\left[\mathrm{Mo}(\mathrm{DPP})(\mathrm{O})\left(\mathrm{H}_{2} \mathrm{O}\right)\right]^{+}(\mathbf{1})$, and Keggin-type POM, $\alpha$-[ $\left[\mathrm{SW}_{12} \mathrm{O}_{40}\right]^{2-}$, employed in this study. 
made by chance as a result of demetalation of $\left[\mathrm{Mo}^{\mathrm{V}}(\mathrm{DPP})(\mathrm{O})\left(\mathrm{H}_{2} \mathrm{O}\right)\right]^{+}$. Thus, a general method to construct PNTs including POMs by utilizing noncovalent interactions, such as hydrogen bonding and $\pi-\pi$ interaction needs to be 5 established. The thermodynamic parameters for the supramolecular assemblies should also be determined in order to understand the interaction in solution.

We report herein a convenient way for construction of a supramolecular assembly, $\left[\left\{\mathrm{Mo}(\mathrm{DPP})(\mathrm{O})\left(\mathrm{H}_{2} \mathrm{O}\right)\right\}_{2}\left(\mathrm{SW}_{12} \mathrm{O}_{40}\right)\right]$

10 (3), composed of $\mathbf{1}$ and a well-defined Keggin-type sulfatungstate $\left(\alpha-\left[\mathrm{SW}_{12} \mathrm{O}_{40}\right]^{2-}\right)^{18}$ in Fig. 1, which are connected via hydrogen bonds to form a 2:1 assembly as revealed by successful X-ray crystal structure determination. In addition, the spectroscopic titration in benzonitrile has 15 allowed us to determine for the first time the thermodynamic parameters for the hydrogen bonding between $\mathrm{Mo}(\mathrm{V})$ porphyrin complex and POM to form a 1:1 assembly in solution.

\section{Experimental section}

${ }_{20}$ General. Chemicals were purchased from commercial sources and used without further purification, unless otherwise noted. Benzonitrile $(\mathrm{PhCN})$ was distilled over $\mathrm{P}_{2} \mathrm{O}_{5}$ and stored over 4 $\AA$ molecular sieves. Acetonitrile $\left(\mathrm{CH}_{3} \mathrm{CN}\right)$ was distilled from $\mathrm{CaH}_{2}$ under Ar just prior to use. All other solvents were 25 special grade and they were used as received from commercial sources without further purification. Column chromatography was performed on a silica gel (Wako-gel C-200 (60-200 mesh)) or activated alumina (ca. 200 mesh), both of which were obtained from Wako pure chemicals. Toluene was

30 distilled over sodium benzophenone ketyl and used for the synthesis of $\mathrm{H}_{2}$ DPP. IR spectra were recorded on a JASCO FT/IR-550 spectrometer $\left(4000-400 \mathrm{~cm}^{-1}\right)$ using $\mathrm{KBr}$ pellets. Variable-temperature (VT) UV-vis spectroscopy was carried out on a Shimazu UV-3600 spectrometer. MALDI-TOF-MS 35 spectra were recorded on a Bruker Daltonics ultrafleXtreme spectrometer using $\alpha$-cyano-4-hydroxycinnamic acid (CHCA) as a matrix. $\left[\mathrm{Mo}(\mathrm{DPP})(\mathrm{O})\left(\mathrm{H}_{2} \mathrm{O}\right)\right] \mathrm{ClO}_{4}{ }^{19}$ (1) and $\alpha$ $(\mathrm{TBA})_{2}\left[\mathrm{SW}_{12} \mathrm{O}_{40}\right]^{18}$ (2) were prepared according to the literature.

$40\left[\left\{\mathbf{M o}(\mathbf{D P P})(\mathbf{O})\left(\mathbf{H}_{2} \mathbf{O}\right)\right\}_{2}\left(\mathbf{S W}_{\mathbf{1 2}} \mathbf{O}_{40}\right)\right] \quad(3) . \quad\left[\mathrm{Mo}(\mathrm{DPP})(\mathrm{O})\left(\mathrm{H}_{2} \mathrm{O}\right)\right]-$ $\mathrm{ClO}_{4}(\mathbf{1})(5.0 \mathrm{mg}, 3.4 \mu \mathrm{mol})$ in $2.5 \mathrm{~mL}$ of ethyl acetate and $\alpha$ $(\mathrm{TBA})_{2}\left[\mathrm{SW}_{12} \mathrm{O}_{40}\right]$ (2) $(3.4 \mathrm{mg}, 1.0 \mu \mathrm{mol})$ in $2.5 \mathrm{~mL}$ of acetonitrile were mixed. The diffusion of hexane vapor into the solution for 3 days at room temperature gave greenish 45 brown crystals of $\mathbf{3}(3.0 \mathrm{mg}, 53 \%)$. The sample was dried in vacuo at $180{ }^{\circ} \mathrm{C}$ for 2 days and then submitted for elemental analysis. Anal. Found: C, 39.83; H, 2.24; N, 1.92. Calc. for $\mathrm{C}_{184} \mathrm{H}_{124} \mathrm{~N}_{8} \mathrm{O}_{44} \mathrm{Mo}_{2} \mathrm{SW}_{12}$ : C, 39.60; H, 2.24; N, 2.01. A single crystal suitable for $\mathrm{X}$-ray crystallography was obtained by

so recrystallization from the same solvent system at room temperature.

Single crystal X-ray crystallography. A single crystal of $\mathbf{3}$ was coated in liquid paraffin and mounted on a glass fiber with silicon grease. X-ray diffraction data were collected on a ${ }_{55}$ Bruker APEX2 diffractometer at $120 \pm 2 \mathrm{~K}$. All calculations for structure refinements were carried out on a personal computer using APEX2 (Bruker) and SHELXL programs. ${ }^{20}$
Electrochemical measurements. Cyclic voltammograms (CV) and differential pulse voltammograms (DPV) were 60 obtained on an ALS 630B electrochemical analyzer in deaerated $\mathrm{PhCN}$ in the presence of $0.1 \mathrm{M}\left[(n \text {-butyl })_{4} \mathrm{~N} \mathrm{PF}_{6}\right.$ $\left(\mathrm{TBAPF}_{6}\right)$ as a supporting electrolyte under $\mathrm{Ar}$ at room temperature, with use of a glassy carbon electrode as a working electrode, $\mathrm{Ag} / \mathrm{AgNO}_{3}$ as a reference electrode, a $\mathrm{Pt}$ ${ }_{65}$ wire as a auxiliary electrode. The values (versus $\mathrm{Ag} / \mathrm{AgNO}_{3}$ ) were converted to those versus SCE by addition of $0.29 \mathrm{~V}^{21}$

\section{Results and discussion}

$\left[\mathrm{Mo}(\mathrm{DPP})(\mathrm{O})\left(\mathrm{H}_{2} \mathrm{O}\right)\right] \mathrm{ClO}_{4}\left(\mathbf{1} \cdot \mathrm{ClO}_{4}\right)^{19}$ in ethyl acetate and $\alpha$ $(\mathrm{TBA})_{2}\left[\mathrm{SW}_{12} \mathrm{O}_{40}\right]\left(\mathrm{TBA}^{+}=\left[\left(n-\mathrm{C}_{4} \mathrm{H}_{9}\right)_{4} \mathrm{~N}\right]^{+}\right)(2)$ in acetonitrile 70 were mixed and kept in hexane vapor for 3 days to give greenish brown crystals. The crystal structure was determined by single-crystal X-ray crystallography as depicted in Fig. 2. As for the Keggin part, the oxygen atoms around sulfur ( $\mathrm{S}(1)$ ) disordered to form two tetrahedrons, and $\mathrm{O}(4), \mathrm{O}(5), \mathrm{O}(6)$ and ${ }_{75} \mathrm{O}(7)$ have 0.5 occupancy, respectively (Fig S1 in ESI). The bond lengths of $\mathrm{Mo}(1)-\mathrm{O}(1)$ and $\mathrm{Mo}(1)-\mathrm{O}(2)$ are 1.671(6) $\AA$ and 2.371(6) $\AA$, respectively, which are comparable to those of bond lengths of $\left[\mathrm{Mo}(\mathrm{DPP})(\mathrm{O})\left(\mathrm{H}_{2} \mathrm{O}\right)\right]^{+}$unit in the porphyrin nanotube. ${ }^{7}$ Thus, we assigned the axial ligands of the

(a)

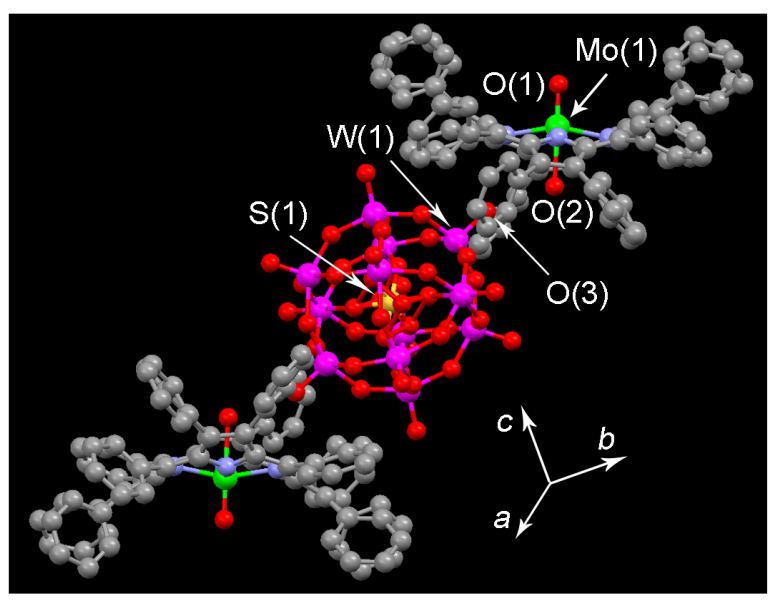

(b)

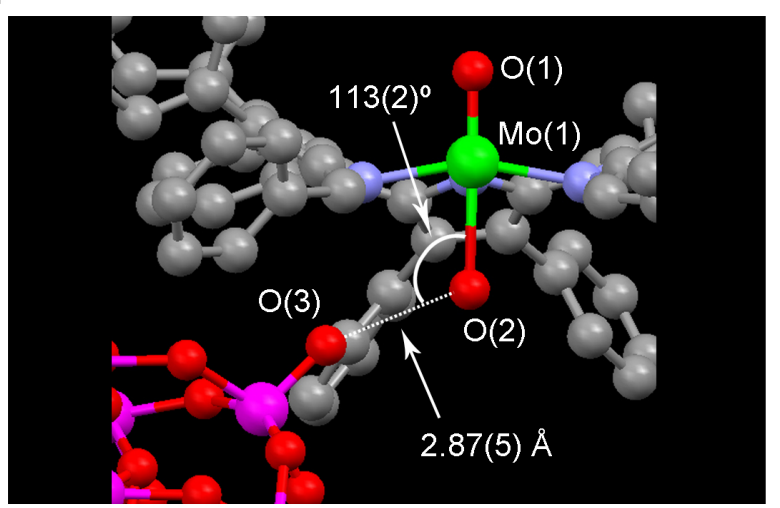

Fig. 2 (a) Crystal Structure of $\left[\left\{\mathrm{Mo}(\mathrm{DPP})(\mathrm{O})\left(\mathrm{H}_{2} \mathrm{O}\right)\right\}_{2}\left(\mathrm{SW}_{12} \mathrm{O}_{40}\right)\right]$ (3) including two hydrogen bonds to form a 2:1 supramolecular assembly (b) A partial view to clarify the hydrogen bond between $\mathrm{O}(2)$ and $\mathrm{O}(3)$. Gray, carbon; blue, nitrogen; red, oxygen; green, molybdenum; 85 pink, tungsten; orange, sulfur. 
porphyrin moiety as $\mathrm{Mo}(\mathrm{V})=\mathrm{O}$ and $\mathrm{Mo}(\mathrm{V})-\mathrm{OH}_{2}$. Moreover, the distance between $\mathrm{O}(2)$ of the aqua ligand of $\mathbf{1}$ and $\mathrm{O}(3)$ of a terminal oxo ligand of $\alpha$-[ $\left[\mathrm{SW}_{12} \mathrm{O}_{40}\right]^{2-}$ is 2.87(1) $\AA$, and the bond angle of $\mathrm{Mo}(1)-\mathrm{O}(2)-\mathrm{O}(3)$ and $\mathrm{O}(2)-\mathrm{O}(3)-\mathrm{W}(1)$ are ${ }_{5} 112.9(2)^{\circ}$ and $152.5(4)^{\circ}$, respectively. Thus, 1 and $\alpha$ $\left[\mathrm{SW}_{12} \mathrm{O}_{40}\right]^{2-}$ should be connected via a hydrogen bond. Hence, the POM is trapped and enclosed by two of $\mathbf{1}$ to form a $1: 2$ supramolecular unit in the crystal (Fig. 2(a)). The selected bond lengths and bond angles are summarized in the 10 Electronic Supplementary Information (Table S1 in ESI). In terms of the charge balance of the unit, the negative charge (2) of POM was cancelled by two of the positively charged $\mathrm{Mo}(\mathrm{V})$-porphyrin units. Based on this crystallographic study and elemental analysis, the formula of this assembly is given 15 as $\left[\left\{\mathrm{Mo}(\mathrm{DPP})(\mathrm{O})\left(\mathrm{H}_{2} \mathrm{O}\right)\right\}_{2}\left(\mathrm{SW}_{12} \mathrm{O}_{40}\right)\right](3)$.

As for the porphyrin moiety in $\mathbf{3}$, the porphyrin macrocycle exhibited saddle-distortion as seen in the precursor 1 . The displacement of each atom from the least-squares mean plane of 24 atoms of the DPP $^{2-}$ ligand is shown in Fig. S2 (see ESI) 20 to clarify the saddle-distortion. Previously, we reported that the distortion porphyrin changed from saddle-distortion to ruffle-distortion by forming a porphyrin hamburger due to the

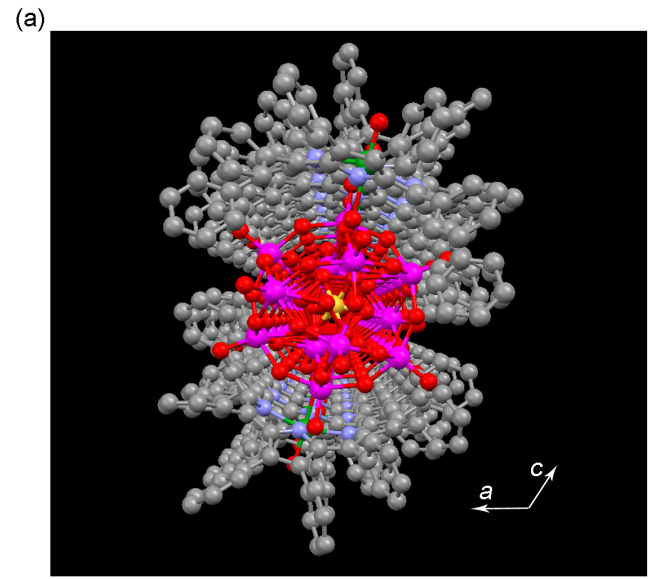

(b)

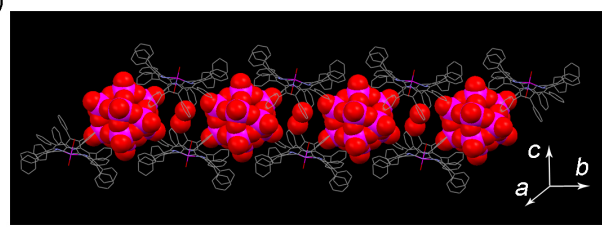

(c)

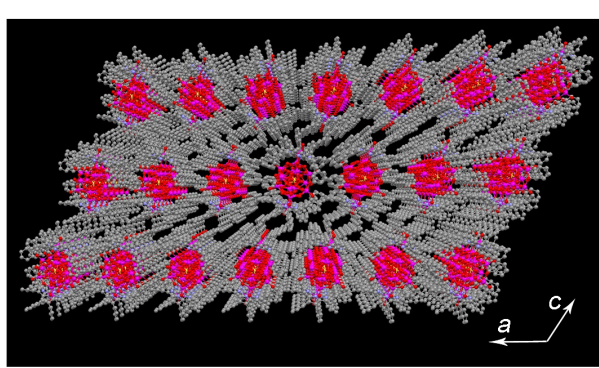

Fig. 3 (a) One-dimensional structure of porphyrin nanotube along the 25 crystallographic $b$ axis. (b) A side view of the porphyrin nanotube (POMs and solvent molecules are shown as space-filling model). (c) Threedimensional crystal packing of $\mathbf{3}$. steric hindrance between phenyl groups and Keggin-type POM. ${ }^{19}$ This is caused by steric congestion due to the direct 30 coordination of POM to the $\mathrm{Mo}(\mathrm{V})$ centre. In the case of $\mathbf{3}$, there is no direct coordination of POM to the $\mathrm{Mn}(\mathrm{V})$ centre but instead hydrogen bond is formed between two components, because the basicity of $\left[\mathrm{SW}_{12} \mathrm{O}_{40}\right]^{2-}$ should be lower than that of $\left[\mathrm{SiW}_{12} \mathrm{O}_{40}\right]^{4-}$ in light of its charge.

35 In the crystal structure, intermolecular $\pi-\pi$ interaction among peripheral phenyl substitutients can be oberved to connect the unit of the 2:1 assembly as depicted in Fig. S3(a) in ESI. Therefore, the 2:1 assemblies are connected and lined along in the direction of the crystallographic $b$ axis to form a 40 supramolecular tubular structure (Fig. 3(a) and 3(b)). In the tubular assembly, a hydrogen-bond network was observed among neighbouring two $\left[\mathrm{Mo}(\mathrm{DPP})(\mathrm{O})\left(\mathrm{H}_{2} \mathrm{O}\right)\right]^{+}$units in $\mathbf{3}$ through water molecules of crystallization (Fig. S3(b) in ESI). Those water molecules are found to disorder, however, the 45 hydrogen-bond network may play a role to bind each unit of the assembly together. These intermolecular $\pi-\pi$ interactions and hydrogen bonds between each unit result in a porphyrin nanotube structure in the direction of the crystallographic $b$ axis in the crystal. Thus, the Keggin-type POM was ${ }_{50}$ encapsulated into a $\pi$-space made of the $\mathrm{Mo}^{\mathrm{V}}$-DPP units via two-point hydrogen bonding with two of 1 . In the threedimensional crystal packing, the porphyrin nanotubes were bundled by $\pi-\pi$ interactions as shown in Fig. 3(c). Moreover, IR spectral data of 1, 2 and $\mathbf{3}$ also indicate that the Keggin 55 structure in $\mathbf{3}$ was maintained, and the ion exchange between $\mathbf{1}$ and 2 took place completely as clarified by the lack of the peaks of $\mathrm{TBA}^{+}$and $\mathrm{ClO}_{4}^{-}$for 3 (Fig. S4 in ESI).

In order to shed some lights on the species in the $\mathrm{CH}_{2} \mathrm{Cl}_{2}$ solution of 3, MALDI-TOF-MS measurements were made. ${ }_{60}$ CHCA ( $\alpha$-cyano-4-hydroxycinnamic acid) was used as a matrix for the measurements. As a result, the observed peak clusters centred at $\mathrm{m} / z=4229.24$ was assigned to a $1: 1$ assembly formulated as $\left[\left\{\mathrm{Mo}(\mathrm{DPP})(\mathrm{O})\left(\mathrm{H}_{2} \mathrm{O}\right)\right\}\left(\mathrm{SW}_{12} \mathrm{O}_{40}\right)\right]^{-}$(4) (Calcd. for $\mathrm{C}_{92} \mathrm{H}_{124} \mathrm{~N}_{4} \mathrm{O}_{42} \mathrm{MoSW}_{12}{ }^{-}$, 4229.59) (see ESI, Fig. ${ }_{65} \mathrm{~S} 5(\mathrm{a})$ ). As a comparison, a planar $\mathrm{Mo}(\mathrm{V})$-porphyrin complex, $\left[\mathrm{Mo}(\mathrm{TPP})(\mathrm{O})\left(\mathrm{H}_{2} \mathrm{O}\right)\right] \mathrm{ClO}_{4} \quad\left(\mathbf{5} \cdot \mathrm{ClO}_{4}\right)^{22} \quad\left(\mathrm{TPP}^{2-}\right.$ : tetraphenylporphyrin dianion), was used to clarify the stronger Lewis acidity of the $\mathrm{Mo}(\mathrm{V})$ ion in $\mathbf{1}$ as discussed below. The reaction mixture of $\mathbf{2}$ and $\mathbf{5}$ in $\mathrm{CH}_{2} \mathrm{Cl}_{2}$ gave peak clusters at $\mathrm{m} / \mathrm{z}=$ 703620.61 which was assigned to a $1: 1$ assembly formulated as $\left[\left\{\mathrm{Mo}(\mathrm{TPP})(\mathrm{O})\left(\mathrm{H}_{2} \mathrm{O}\right)\right\}\left(\mathrm{SW}_{12} \mathrm{O}_{40}\right)\right]^{-} \quad$ (6) (Calcd. for $\mathrm{C}_{44} \mathrm{H}_{30} \mathrm{~N}_{4} \mathrm{O}_{42} \mathrm{MoSW}_{12}{ }^{-}, 3620.81$ ) (see ESI, Fig. S5(b)).

Variable-temperature (VT) UV-vis spectroscopic titration of $\mathbf{1} \cdot \mathrm{ClO}_{4}$ by adding $\mathbf{2}$ in $\mathrm{PhCN}$ was performed to estimate the 75 strength of the hydrogen bonding in the $1: 1$ assembly 4 . The result of spectroscopic titration at $293 \mathrm{~K}$ is shown in Fig. 4(a). The spectral change observed can be assigned to that derived from the formation of a 1:1 assembly between 1 and POM, i.e. $\left[\mathrm{Mo}(\mathrm{DPP})(\mathrm{O})\left(\mathrm{H}_{2} \mathrm{O}\right)\left(\mathrm{SW}_{12} \mathrm{O}_{40}\right)\right]^{-}$(4), due to hydrogen bond 80 formation. The equilibrium constants were determined at 265 , 273, 283, 293, 303 and $313 \mathrm{~K}$, and the results are summarized in Table 1 (see also Figs S6 - S9 in ESI).

The VT-UV-vis spectroscopic titration allowed us to have an $R \ln K$ versus $1 / T$ plot (van't Hoff plot) as shown in Fig. 5 ${ }_{85}\left(R=8.31 \mathrm{~J} \mathrm{~K}^{-1} \mathrm{~mol}^{-1}\right)$. The heat of formation $(\Delta H)$ and 
(a)

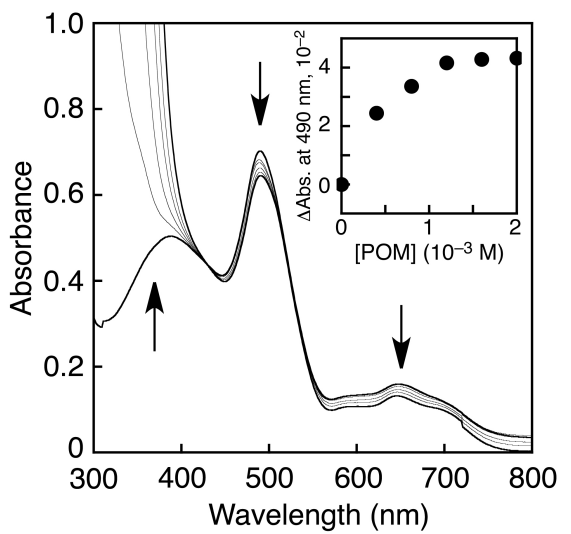

(b)

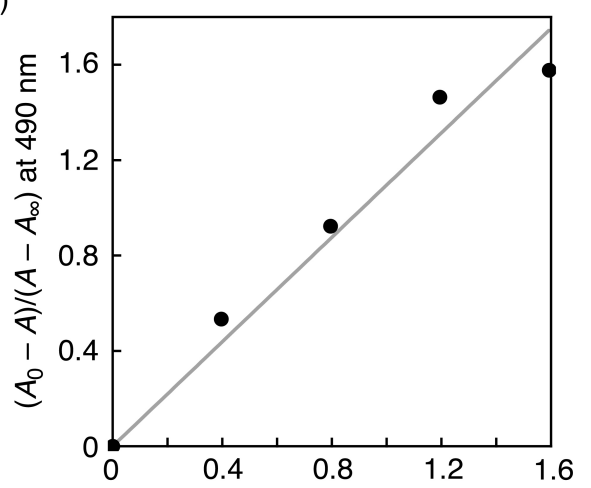

Fig. $4\left(\mathrm{a}, \ldots\right.$, $\left.\left.([\mathrm{POM}]-\alpha[\text { por }]]_{0}\right)\left(10^{-3} \mathrm{M}\right) \ldots \quad \mathrm{M}\right)$ upon addition of 2 in $\mathrm{PhCN}$ at $293 \mathrm{~K}$. $\triangle \mathrm{Abs}\left(A_{0}-A\right)$ at $490 \mathrm{~nm}$ was plotted as an inset. (b) Plot of $\left(A_{0}-A\right) /\left(A-A_{\infty}\right)$ at $490 \mathrm{~nm}$ versus ([POM] $\left.{ }_{5} \alpha[\text { por }]_{0}\right)$. From the slope of the linear correlation the equilibrium constant $K$ is determined to be $1.1 \times 10^{3} \mathrm{M}^{-1}$.

Table 1 Equilibrium constants $(K)$ for the supramolecular assembly 4 and 6 in $\mathrm{PhCN}$ at each temperature

\begin{tabular}{lll}
\hline & \multicolumn{2}{c}{$K\left(\mathrm{M}^{-1}\right)$} \\
\cline { 2 - 3 } Temperature (K) & $\mathbf{4}$ & $\mathbf{6}$ \\
\hline 265 & $4.5 \times 10^{2}$ & $2.3 \times 10^{3}$ \\
273 & $6.1 \times 10^{2}$ & $2.7 \times 10^{3}$ \\
283 & $7.8 \times 10^{2}$ & $3.2 \times 10^{3}$ \\
293 & $1.1 \times 10^{3}$ & $4.0 \times 10^{3}$ \\
303 & $1.8 \times 10^{3}$ & $5.5 \times 10^{3}$ \\
313 & $2.5 \times 10^{3}$ & $6.7 \times 10^{3}$ \\
\hline
\end{tabular}

10 entropy change $(\Delta S)$ were determined to be $\Delta H=24 \pm 2 \mathrm{~kJ}$ $\mathrm{mol}^{-1}$ and $\Delta S=141 \pm 5 \mathrm{~J} \mathrm{~K}^{-1} \mathrm{~mol}^{-1}$ for 4 (Table 2). When $5 \cdot \mathrm{ClO}_{4}$ was used in the measurements, the spectral change with the addition of $\mathbf{2}$ afforded larger equilibrium constants compared to those of $\mathbf{1}$ with $\mathbf{2}$ at each temperature (Table 1, 15 see ESI). In this case, 5 forms a 1:1 hydrogen-bonded assembly 6 with $\alpha$-[ $\left[\mathrm{SW}_{12} \mathrm{O}_{40}\right]$ in solution. The van't Hoff plot for 6 was made to determine the $\Delta H$ and $\Delta S$ values to be $16 \pm$ $1 \mathrm{~kJ} \mathrm{~mol}^{-1}$ and $122 \pm 4 \mathrm{~J} \mathrm{~K}^{-1} \mathrm{~mol}^{-1}$, respectively (Fig. 5). The values of $\Delta H$ and $\Delta S$ for 4 and $\mathbf{6}$ in $\mathrm{PhCN}$ are summarized in 20 Table 2.

In both cases, the results indicate that the hydrogen bond

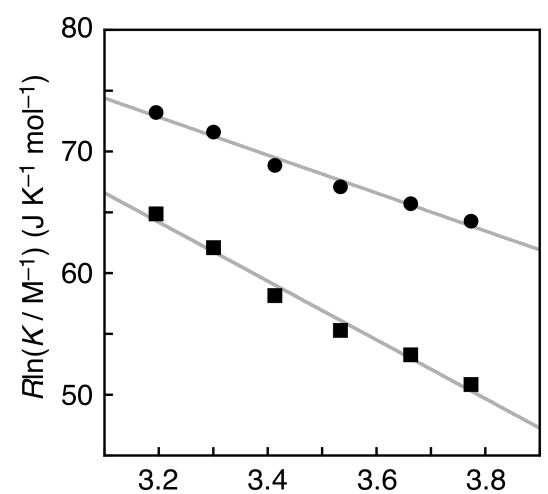

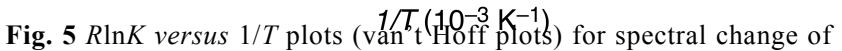
$\mathbf{3}(\mathbf{\square})$ and $\mathbf{5}(\bullet)$ upon addition of $\mathbf{2}\left(\left[\mathbf{1} \cdot \mathrm{ClO}_{4}\right]=1.0 \times 10^{-5} \mathrm{M},\left[4 \cdot \mathbf{C l O}_{4}\right]\right.$ $\left.25=2.0 \times 10^{-5} \mathrm{M}\right)$.

Table 2 The heat of formation $(\Delta H)$ and entropy change $(\Delta S)$ for 4 and 6 in $\mathrm{PhCN}$

\begin{tabular}{lll}
\hline Entry & $\Delta H\left(\mathrm{~kJ} \mathrm{~mol}^{-1}\right)$ & $\Delta S\left(\mathrm{~J} \mathrm{~K}^{-1} \mathrm{~mol}^{-1}\right)$ \\
\hline $\mathbf{4}$ & $24 \pm 2$ & $141 \pm 5$ \\
$\mathbf{6}$ & $16 \pm 1$ & $122 \pm 4$ \\
\hline
\end{tabular}

formation of the aqua ligands of $\mathbf{1}$ and $\mathbf{5}$ with $\alpha$-[ $\left[\mathrm{SW}_{12} \mathrm{O}_{40}\right]^{2-}$ 30 is a entropy-controlled process, as represented by the larger $K$ values at higher temperature (Table 1) and the positively large $\Delta S$ values in both cases. The positive entropy change may result from the dissociation of counterions of both components, which are hydrogen-bonded $\mathrm{ClO}_{4}{ }^{-}$for the ${ }_{35} \mathrm{Mo}(\mathrm{V})$-porphyrin complexes $\left(\mathbf{1} \cdot \mathrm{ClO}_{4}{ }^{19 b, 23}\right.$ and $\left.\mathbf{5} \cdot \mathrm{ClO}_{4}{ }^{22}\right)$ and electrostatically interacting $\mathrm{TBA}^{+}$for $\alpha-\left[\mathrm{SW}_{12} \mathrm{O}_{40}\right]^{2-}$. The positive $\Delta H$ values suggest that the dissociation energy of the counterions is larger than stabilization energy due to the hydrogen bond formation with the POM in both $\mathbf{4}$ and $\mathbf{6}$. This 40 result may reflect the charge density of an oxygen atom in $\mathrm{ClO}_{4}^{-}$and $\alpha$ - $\left[\mathrm{SW}_{12} \mathrm{O}_{40}\right]^{2-}$ involved in the hydrogen bonding. Though the minus charge of $\alpha-\left[\mathrm{SW}_{12} \mathrm{O}_{40}\right]^{2-}$ is larger than that of $\mathrm{ClO}_{4}^{-}$, it should be delocalized over forty oxygen atoms in $\alpha-\left[\mathrm{SW}_{12} \mathrm{O}_{40}\right]^{2-}$ besides that delocalized over four oxygen 45 atoms in $\mathrm{ClO}_{4}^{-}$. Therefore, $\alpha-\left[\mathrm{SW}_{12} \mathrm{O}_{40}\right]^{2-}$ is a weaker base than $\mathrm{ClO}_{4}^{-}$and the hydrogen bonding between 1 and $\alpha$ $\left[\mathrm{SW}_{12} \mathrm{O}_{40}\right]^{2-}$ should be weaker than that between $\mathbf{1}$ and $\mathrm{ClO}_{4}{ }^{-}$ to give the positive $\Delta H$ values.

The larger $\Delta H$ value of 4 than that of $\mathbf{6}$ (Table 2) indicates so that the dissocication energy of the couterion, especially $\mathrm{ClO}_{4}^{-}$for $\mathbf{1}$, is larger than that for $\mathbf{2}$. This result should be ascribed to the fact that the distortion of the porphyrin ligand can enhance the Lewis acidity of the $\mathrm{Mo}(\mathrm{V})$ centre to strengthen the acidity of the aqua ligand, ${ }^{24}$ giving rise to a 55 stronger hydrogen bonding between 1 and $\mathrm{ClO}_{4}^{-}$than that for the planar counterpart of $\mathbf{2}$. This stronger hydrogen bond between 1 and $\mathrm{ClO}_{4}^{-}$results in the lower $K$ values of $\mathbf{4}$ than those of $\mathbf{6}$. The lower $K$ value of $\mathbf{4}$ may also be derived from a steric hindrance between the DPP ${ }^{2-}$ ligand and the POM.

60 Cyclic voltammograms (CV) and differential pulse voltammograms (DPV) of $\mathbf{1}, \mathbf{2}$ and $\mathbf{4}$ were obtained in deaerated $\mathrm{PhCN}$ at room temperature under $\mathrm{Ar}$ in the presence 
of $0.10 \mathrm{M} \mathrm{TBAPF}_{6}$ as a supporting electrolyte (Fig. 6). On the basis of the equilibrium constant, the concentration for 1 ( 5 $\mathrm{mM})$ and $2(5 \mathrm{mM})$ were used to form a 1:1 assembly 4 in $\mathrm{PhCN}$. Assignments of redox waves are summarized in Table 53. The redox wave due to the $\mathrm{Mo}^{\mathrm{V}} / \mathrm{Mo}^{\mathrm{IV}}$ couple ${ }^{25}$ for 4 undergoes severe overlap with that of $\mathrm{POM}^{2-} / \mathrm{POM}^{3-}$ as indicated by the doubled peak current for the redox wave observed at $-0.12 \mathrm{~V}$ as compared to those of other waves. Therefore, we could not determine precisely those potentials 10 for 4 . The redox potentials of the first oxidation, the first reduction and the second reduction of the $\mathrm{DPP}^{2-}$ ligand were determined to be $+1.12,-1.21$ and $-1.63 \mathrm{~V}$ (vs SCE), respectively, for the assembly $\mathbf{4}$ in comparison with those of $\mathbf{1}$ $\left(+1.28,-1.03\right.$ and $-1.42 \mathrm{~V}$; Fig. S10(a) in ESI). ${ }^{26}$ All the 15 redox potentials for the $\mathrm{DPP}^{2-}$ ligand showed cathodic shift: This is ascribed to the larger ring distortion of the porphyrin ligand than that in $\mathbf{1}$, as reflected on the larger $\Delta R M S^{27}$ value of $3(0.70 \AA)$ than that of $\mathbf{1}(0.67 \AA)$. This is probably derived from the steric repulsion between the $\mathrm{DPP}^{2-}$ ligand and the ${ }_{20} \mathrm{POM}$ anion. The larger distortion weakens the interaction between the $\mathrm{DPP}^{2-}$ ligand and the $\mathrm{Mo}(\mathrm{V})$ centre to render the porphyrin ring more electron-rich to lower the redox potentials. In contrast, the redox potentials of the POM moiety in 4 exhibited slightly positive shifts as compared to those of ${ }_{25} 2$ (Table 3 and Fig. S10(b) in ESI). This is reasonably ascribed to the result of the hydrogen bond formation of $\alpha$ -
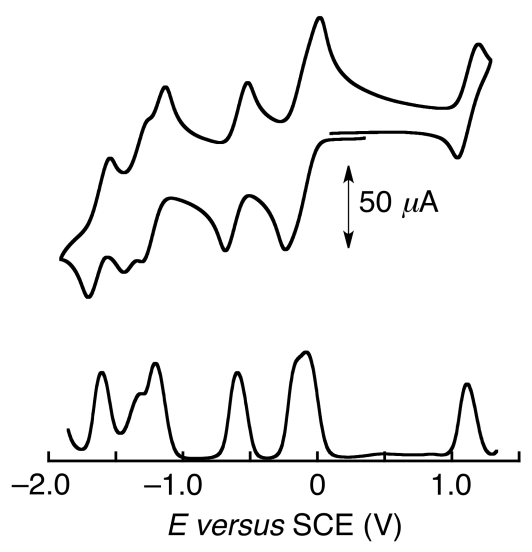

Fig. 6 Cyclic voltammogram (CV) and differential pulse voltammogram (DPV) for $1(5 \mathrm{mM})$ with $2(5 \mathrm{mM})$ in $\mathrm{PhCN}$ at room 30 temperature under $\mathrm{Ar}$ in the presence of $0.1 \mathrm{M} \mathrm{TBAPF}_{6}$.

Table 3 Redox potentials of $1(1.0 \mathrm{mM}), \mathbf{2}(1.0 \mathrm{mM})$ and $1(5.0 \mathrm{mM})$ with $2(5 \mathrm{mM})$ in $\mathrm{PhCN}^{a}$

\begin{tabular}{llll}
\hline & \multicolumn{3}{c}{ Eversus SCE, V $(\Delta E)^{b}$} \\
\cline { 2 - 4 } & $\mathbf{1}$ & $\mathbf{2}$ & $\mathbf{1}+\mathbf{2}(\mathbf{4})$ \\
\hline $\mathrm{Mo}^{\mathrm{IV}} / \mathrm{Mo}^{\mathrm{V}}$ & $0.03(0.07)$ & - & $-0.12(0.24)^{d}$ \\
$\mathrm{Por}^{2-} / \mathrm{Por}^{-c}$ & $1.28(0.08)$ & - & $1.12(0.15)$ \\
$\mathrm{Por}^{3-} / \mathrm{Por}^{2-}$ & $-1.03(0.07)$ & - & $-1.21(0.16)$ \\
$\mathrm{Por}^{4-} / \mathrm{Por}^{5-}$ & $-1.42(0.08)$ & - & $-1.63(0.16)$ \\
$\mathrm{POM}^{3-} / \mathrm{POM}^{2-}$ & - & $-0.08(0.09)$ & $-0.12(0.24)^{d}$ \\
$\mathrm{POM}^{4-} / \mathrm{POM}^{3-}$ & - & $-0.61(0.13)$ & $-0.60(0.16)$ \\
$\mathrm{POM}^{5-} / \mathrm{POM}^{4-}$ & - & $-1.37(0.20)$ & $-1.32(0.17)$
\end{tabular}

${ }^{a}$ At room temperature under $\mathrm{Ar} ; 0.1 \mathrm{M} \mathrm{TBAPF}_{6}$ as a supporting electrolyte. ${ }^{b} \Delta E=E_{\text {ox }}-E_{\text {red }}(\mathrm{V}) .{ }^{c}$ Por $^{\mathrm{n}-}: \mathrm{DPP}^{2-}$ ligand. ${ }^{d}$ Overlapped.
$\left[\mathrm{SW}_{12} \mathrm{O}_{40}\right]^{2-}$ with $\mathbf{1}$ to interact with an acidic hydrogen in the aqua ligand of 1 . Thus, the electrochmical measurements lend 35 credence to the interaction of the POM anion with $\mathbf{1}$ by hydrogen bonding in solution.

\section{Summary}

We have succeeded in the formation and the crystal structure determination of a novel Porphyrin Nanotube using a Keggin40 type POM as a well-defined structural motif and a saddledistorted $\mathrm{Mo}^{\mathrm{V}}$-porphyrin complex by virtue of intermolecular hydrogen bonding. The thermodynamic analysis allowed us to demonstrate the formation of the supramolecular assembly for the first time between the POM and the saddle-distorted 45 metalloporphyrin as an entropy-controlled process rather than an enthalpy-controlled one. The MALDI-TOF mass spectrometry and electrochemical measurements lend credence to the stability of the hydrogen-bonded supramolecular assembly even in solution. The methodology ${ }_{50}$ presented herein would provide a new strategy to design and prepare POM-based supramolecular architecture with use of metalloporphyrins.

\section{Acknowledgements}

We are grateful to financial support provided by Grants-in${ }_{55}$ Aid (Nos. 20108010 and 21111501) and a Global COE program, "the Global Education and Research Centre for BioEnvironmental Chemistry" from the Japan Society of Promotion of Science (JSPS), a JSPS predoctral fellowship (20-00804 to A. Y.) and by KOSEF/MEST through WCU 60 project (R31-2008-10010-0).

\section{Notes and references}

+ Crystal data for 3. $\mathrm{C}_{192} \mathrm{H}_{142} \mathrm{Mo}_{2} \mathrm{~N}_{8} \mathrm{O}_{50} \mathrm{SW}_{12}, M=5791.28$, triclinic, $a=16.185(2), b=17.072(2), c=20.604(3) \AA, \alpha=$ 91.431(2), $\beta=111.262(2)^{\circ}, \gamma=116.401(2)^{\circ}, V=4633(1) \AA^{3}$, ${ }_{65} T=120(2) \mathrm{K}$, space group $P-1, Z=1,22139$ reflections measured, 16151 number of independent reflections, $R($ int $)=$ 0.022 , The final $R 1\left(R_{\mathrm{w}}\right)=0.040(0.092)(I>2 \sigma(I))$ and $R\left(R_{\mathrm{w}}\right)$ $=0.059(0.106)$ (for all data), $\mathrm{GOF}=1.026$. CCDC 791022 contains the supplementary crystallographic data for this 70 paper. These data can be obtained free of change from The Cambridge Crystallographic Data Centre via www.ccdc.cam.ac.uk/data request/cif.

1 (a) A. J. Hoff and J. Deisenhofer, Phys. Rep., 1997, 287, 1-247; (b) Anoxygenic Photosynthetic Bacteria, ed. R. E. Blankenship, M. T. Madigan and C. E. Bauer, Kluwer Academic Publishers, Dordrecht, 1995.

2 (a) P. Heathcote, P. K. Fyfe and M. R. Jones, Trends Biochem. Sci., 2002, 27, 79-87; (b) M. H. B. Stowell, T. M. McPhillips, D. C. Rees, S. M. Soltis, E. Abresch and G. Feher, Science, 1997, 276, 812-816; (c) A. Remy and K. Gerwert, Nature Struct. Biol., 2003, 10, 637-644.

3 Z. Wang, L. E. Lybarger, W. Wang, C. J. Medforth, J. E. Miller and J. A. Shelnutt, Nanotechnology, 2008, 19, 395604.

4 (a) T. Hasobe, H. Imahori, P. V. Kamat and S. Fukuzumi, J. Am. 85 Chem. Soc., 2003, 125, 14962-14963; (b) T. Hasobe, H. Imahori, P. V. Kamat, T. K. Ahn, D. Kim, T. Hanada, T. Hirakawa and S. Fukuzumi, J. Am. Chem. Soc., 2005, 127, 1216-1228.

5 Z. C. Wang, Z. Y. Li, C. J. Medforth and J. A. Shelnutt, J. Am. Chem. Soc., 2007, 129, 2440-2441.

906 (a) Z. C.Wang, C. J. Medforth and J. A. Shelnutt, J. Am. Chem. Soc., 2004, 126, 15954-15955; (b) R. Franco, J. L. Jacobsen, H. Wang, Z. 
Wang, K. István, N. E. Schore, Y. Song, C. J. Medforthcd and J. A. Shelnutt, Phys. Chem. Chem. Phys., 2010, 12, 4072-4077.

7 (a) R. Harada, Y. Matsuda, H. Okawa and T. Kojima, Angew. Chem. Int. Ed., 2004, 43, 1825-1828; (b) T. Kojima, R. Harada, T. Nakanishi, K. Kaneko and S. Fukuzumi, Chem. Mater., 2007, 19, 5158.

8 (a) H. Nobukuni, Y. Shimazaki, F. Tani and Y. Naruta, Angew. Chem., Int. Ed., 2007, 46, 8975-8978; (b) H. Nobukuni, F. Tani, Y. Shimazaki, Y. Naruta, K. Ohkubo, T. Nakanishi, T. Kojima, S. $10 \quad$ Fukuzumi and S. Seki, J. Phys. Chem. C, 2009, 113, 19694-19699; (c) H. Nobukuni, Y. Shimazaki, H. Uno, Y. Naruta, K. Ohkubo, T. Kojima, S. Fukuzumi, S. Seki, H. Sakai, T. Hasobe and F. Tani, Chem.-Eur. J., 2010, 16, 11611-11623.

9 Z. Wang, K. J. Ho, C. J. Medforth and J. A. Shelnutt, $A d v$. Mater., 2006, $18,2557-2556$.

10 J. H. Jang, K. S. Jeon, S. Oh, H. J. Kim, T. Asahi, H. Masuhara and M. Yoon, Chem. Mater., 2007, 19, 1984-1991.

11 (a) Y. Kim, M. F. Mayer and S. C. Zimmerman, Angew. Chem., Int. Ed., 2003, 42, 1121-1126; (b) T. Yamaguchi, N. Ishii, K. Tashiro and T. Aida, J. Am. Chem. Soc., 2003, 125, 13934-13935; (c) K. Hosomizu, M. Oodoi, T. Umeyama, Y. Matano, K. Yoshida, S. Isoda, M. Isosomppi, N. V. Tkachenko, H. Lemmetyinen and H. Imahori, $J$. Phys. Chem. B, 2008, 112, 16517-16524.

12 (a) T. Kojima, T. Honda, K. Ohkubo, M. Shiro, T. Kusukawa, T.

25 Fukuda, N. Kobayashi and S. Fukuzumi, Angew. Chem., Int. Ed., 2008, 47, 6712-6716; (b) S. Fukuzumi, T. Honda, K. Ohkubo and T. Kojima, Dalton Trans., 2009, 3880-3889.

13 (a) R. Harada and T. Kojima, Chem. Commun., 2005, 716-718; (b) T. Kojima, T. Nakanishi, R. Harada, K. Ohkubo, S. Yamauchi and S.

$30 \quad$ Fukuzumi, Chem. Eur. J., 2007, 13, 8714-8725; (c) S. Fukuzumi and T. Kojima, J. Mater. Chem., 2008, 18, 1427-1439; (d) T. Nakanishi, T. Kojima, K. Ohkubo, T. Hasobe, K. Nakayama and S. Fukuzumi, Chem. Mater., 2008, 20, 7492-7500.

14 (a) I. V. Kozhevnikov, Chem. Rev., 1998, 98, 171-198; (b) R. Neumann and M. Dahan, J. Am. Chem. Soc., 1998, 120, 1196911976; (c) N. Azizi, L. Torkiyan and M. R. Saidi, Org. Lett., 2006, 8, 2079-2082; (d) K. Kamata, K. Yonehara, Y. Sumida, K. Yamaguchi, S. Hikichi and N. Mizuno, Science, 2003, 300, 964-966; (e) S. Bareyt, S. Piligkos, B. Hasenknopf, P. Gouzerh, E. Lacôte, S. Thorimbert and M. Malacria, J. Am. Chem. Soc., 2005, 127, 6788-6794; (f) L.-H. Bi, G. Al-Kadamany, E. V. Chubarova, M. H. Dickman, L. Chen. D. S. Gopala, R. M. Richards, B. Keita, L. Nadjo, H. Jaensch, G. Mathys and U. Kortz, Inorg. Chem., 2009, 48, 10068-10077.

15 (a) X. Fang, P. Kogerler, L. Isaacs, S. Uchida and N. Mizuno, J. Am. Chem. Soc., 2009, 131, 432-433; (b) T. Akutagawa, D. Endo, S.-I. Noro, L. Cronin and T. Nakamura, Coord. Chem. Rev., 2007, 251, 2547-2561; (c) T. Chatterjee, M. Sarma, S. K. Das, Cryst. Growth Des., 2010, 10, 3149-3163.

16 (a) Y. Ishii, Y. Takenaka and K. Konishi, Angew. Chem., Int. Ed.,

50 2004, 43, 2702-2705; (b) Y. Ishii, N. Nakayama and K. Konishi, Chem. Lett., 2007, 36, 246-247.

17 (a) G. Bazzan, W. Smith, L. C. Francesconi and C. M. Drain, Langmuir, 2008, 24, 3244-3249; (b) C. Allain, S. Favette, L.-M. Chamoreau, J. Vaissermann, L. Ruhlmann and B. Hasenknopf, Eur. J. Inorg. Chem., 2008, 3433-3441; (c) D. Schaming, C. Allain, R. Farha, M. Goldmann, S. Lobstein, A. Giraudeau, B. Hasenknopf and L. Ruhlmann, Langmuir, 2010, 26, 5101-5109.

18 S. Himeno, M. Takamoto, M. Hoshiba, A. Higuchi and M. Hashimoto, Bull. Chem. Soc. Jpn., 2004, 77, 519-524.

6019 (a) A. Yokoyama, T. Kojima, K. Ohkubo and S. Fukuzumi, Chem. Commun., 2007, 3997-3999. (b) A. Yokoyama, T. Kojima, K. Ohkubo and S. Fukuzumi, Inorg. Chem. 2010, 49, 11190-11198.

20 G. M. Sheldrick, SHELX 97, Program for Crystal Structures Refinement; University of Göttingen, Germany, 1997.

${ }_{65} 21$ C. K. Mann and K. K. Barnes, Electrochemical Reactions in Nonaqueous Systems, Marcel Dekker: New York, 1990.

22 B. J. Hamstra, B. Cheng, M. K. Ellison and W. R. Scheidt, Inorg. Chem., 1999, 38, 3554-3561.

23 The severe disorder of three $\mathrm{CH}_{2} \mathrm{Cl}_{2}$ molecles in the crystal of $\mathbf{1} \cdot \mathrm{ClO}_{4}$

70 has precluded the discussion on the detailed structure. For the preparation and crystal structure of $\mathbf{1} \cdot \mathrm{ClO}_{4}$, see: reference $19(\mathrm{~b})$ and its Supporting Information.

24 T. Kojima, T. Nakanishi, T. Honda, R. Harada, M. Shiro and S. Fukuzumi, Eur. J. Inorg. Chem., 2009, 727-734.

7525 T. Malinski, P. M. Hanley and K. M. Kadish, Inorg. Chem., 1986, 25, 3229-3235.

26 R. Guilard, K. Perié, J.-M. Barbe, D. J. Nurco, K. M. Smith, E. V. Caemelbecke and K. M. Kadish, Inorg. Chem., 1998, 37, 973-981.

$27 \Delta R M S-\sqrt{\frac{1}{24} \sum_{i=1}^{24} \delta_{i}^{2}}$

$80 \quad$ where $\delta_{\mathrm{i}}$ is deviation of atom $i$ in the 24 atoms of the prophyrin core from the least-squares porphyrin mean plane. See: T. Nakanishi, K. Ohkubo, T. Kojima and S. Fukuzumi, J. Am. Chem. Soc., 2009, 131, 577-584. 


\section{Table of Contents}

A 2:1 supramolecular assembly of a saddle-distorted Mo(V)porphyrin complex and a Keggin-type heteropolyoxometalate was formed via hydrogen bonds. The formation of the assembly 5 was revealed to occur as an entropy-controlled process.

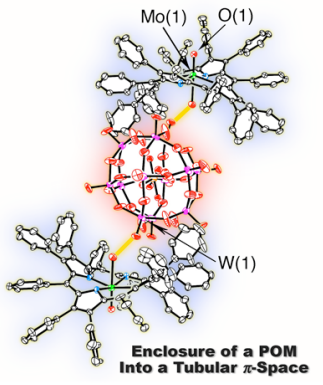

